\title{
Persepsi Masyarakat terhadap Status Kawasan Suaka Margasatwa Ko'mara Kabupaten Takalar
}

\author{
Hamdan ${ }^{1, *}$, Amran Achmad ${ }^{2}$, Asar Said Mahbub² \\ ${ }^{1}$ Mahasiswa Pascasarjana IImu Kehutanan, Universitas Hasanuddin \\ ${ }^{2}$ Fakultas Kehutanan Fakultas Kehutanan, Universitas Hasanuddin \\ *E-mail: hamdanhasbullah82@yahoo.com
}

\begin{abstract}
The management of protected areas and the surrounding community is an inseparable part. Community around the forest area is a component that interacts directly with the forest area. Interaction of the community with the forest area is influenced by the community's perception of the forest itself. This research was carried out at hamlet which bordered directly on Ko'mara Wildlife Reserve. Data collection was done by field observation, interview, questionnaire and study literature. The level of perception is determined by means of scoring techniques and the factors influencing the perception of the community are described descriptively. The results showed that: (1) the public perception on Karemanepasan and Karepatodo hamlet is moderate, while Ballaborong hamlet is low. (2) Age of the respondent in the productive age range, there is still a chance for a change in perception towards better. The low level of education of respondents influences the insight and way of thinking in the perception of the forest area. The work of the interviewees as farmers, who are heavily dependent on forests as water suppliers for their farms, can form a positive perception. Community engagement can be generally positive because the community can be a means of advising the reserve by the Area Manager.
\end{abstract}

Keywords: Perception; Society; Conservation area; Ko'mara wlldlife reserve DOI: http://dx.doi.org/10.24259/jhm.v9i2.2974

\section{PENDAHULUAN}

Salah satu kawasan hutan yang telah ditunjuk oleh Pemerintah sebagai kawasan konservasi adalah Suaka Margasatwa Ko'mara. Kawasan ini ditetapkan berdasarkan Surat Keputusan Menteri Kehutanan No. 911/Kpts-II/1999 tanggal 14 Oktober 1999 seluas $2.972 \mathrm{Ha}$. Secara administrasif pemerintahan terletak di Kecamatan Polombangkeng Utara Kabupaten Takalar dan di Kecamatan Bungaya Kabupaten Gowa Provinsi Sulawesi Selatan. Berdasarkan organisasi pengelolaan, kawasan ini termasuk dalam wilayah kerja Seksi Konservasi Wilayah III Soppeng, Bidang KSDA Wilayah II Parepare, Balai Besar KSDA Sulawesi Selatan.

Suaka Margasatwa Ko'mara menghadapi permasalahan yang dapat mengganggu keutuhan kawasan, diantaranya adalah aktivitas masyarakat didalam dan disekitar kawasan dalam memanfaatkan sumber daya alam. Masyarakat memanfaatkan hasil hutan bukan kayu seperti madu alam, nira aren dan kayu bakar karena pada awalnya merupakan kawasan Hutan lindung, kemudian beralih fungsi menjadi kawasan suaka alam yang menutup ruang bagi masyarakat sekitar kawasan untuk memanfaatkan sumber daya alam yang ada didalam kawasan. Perubahan status dan fungsi hutan dapat berpengaruh pada putusnya hubungan masyarakat dengan hutan atau bahkan kemungkinan hilangnya mata pencaharian masyarakat (Muntu, 2012).

Pengelolaan kawasan konservasi dan pembinaan masyarakat disekitarnya adalah bagian yang tidak dapat dipisahkan. Masyarakat sekitar kawasan merupakan komponen yang berinterakasi secara langsung dengan kawasan hutan. Jika interaksi masyarakat merupakan tindakan yang dapat merusak maka keberadaannya akan menjadi ancaman terhadap keutuhan kawasan hutan. Tekanan masyarakat di daerah penyangga kedalam kawasan merupakan dampak dari beberapa faktor seperti kepentingan dalam mata pencaharian, tingkat pendidikan, tingkat kepadatan penduduk, dan kepemilikanlahan (Sawitri, 2013). 
Informasi tentang persepsi masyarakat yang terlibat langsung dalam pemanfaatan sumberdaya hayati hutan sangat dibutuhkan untuk mencoba menjawab bagaimana persepsi masyarakat sekitar kawasan terhadap Suaka Margasatwa Ko'mara. Oleh karena itu, tujuan penelitian untuk menjawab tingkat dan faktor-faktor yang mempengaruhi persepsi masyarakat terhadap kawasan Suaka Margasatwa Ko'mara.

\section{METODOLOGI PENELITIAN}

\subsection{Tempat dan Waktu}

Penelitian ini dilaksanakan pada dusun Ballaborong, Karemanepasa, dan Karepatodo yang mempunyai wilayah administratif berbatasan langsung dengan kawasan Suaka Margasatwa Ko'mara, Kabupaten Takalar. Penelitian ini dilaksanakan selama 4 bulan mulai dari bulan Januari sampai dengan April 2016.

\subsection{Bahan dan Alat Penelitian}

Alat dan bahan yang akan digunakan dalam penelitian ini adalah alat tulis menulis, timer, alat perekam (voice recorder), kamera, kuesioner, dan perlengkapan lapangan lainnya. Untuk pengolahan data digunakan perangkat lunak seperti Microsoft Office 2007 (Word, Excel, Powerpoint, oneNote), dan ArcGIS 9.3.

\subsection{Pengumpulan Data}

Data yang diperlukan dalam penelitian ini meliputi data primer dan sekunder. Data primer adalah data yang diperoleh dengan melakukan wawancara langsung. Data sekunder diperoleh dari beberapa instansi terkait seperti Kantor Kecamatan Polombangkeng Utara, Kantor Desa Barugaya dan Balai Besar Konservasi Sumber Daya Alam Resort Ko'mara. Data sekunder berupa data Kabupaten Takalar dalam angka 2014, Kecamatan Polombangkeng Utara dalam angka 2014 dan kawasan konservasi di Sulawesi Selatan. Selain data dari instansi, data sekunder juga diperoleh dari studi pustaka dan hasil penelitian terdahulu yang masih relevan dan valid untuk keperluan penelitian.

Metode mengambilan sampel adalah secara sengaja (purposive sampling), dengan mempertimbangkan sebaran lokasi. Sampel yang dipilih adalah rumah tangga, sehingga responden adalah kepala rumah tangga. Pengambilan sampel dilakukan pada 3 dusun yang berbatasan langsung dengan kawasan Suaka Margasatwa Ko'mara. Populasi pada ketiga dusun tersebut adalah $408 \mathrm{KK}$, penentuan jumlah responden didasarkan menurut Arikunto (1998), Apabila subjeknya kurang dari 100, lebih baik diambil semua (sensus) sehingga penelitiannya merupakan penelitian populasi. Selanjutnya jika jumlah subjeknya besar dapat diambil antara 10 $15 \%$. Sehingga total minimal sampel atau responden adalah 41 orang. Adapun besar atau jumlah pembagian responden untuk masing-masing dusun dengan mengunakan rumus menurut Sugiyono (2012).

$$
n=\frac{X}{N} x N 1
$$

keterangan :

$\mathrm{n}$ : jumlah sampel yang diinginkan setiap strata

$\mathrm{N}$ : jumlah populasi

$X$ : jumlah populasi pada setiap strata

N1: jumlah sampel minimum 
Sehingga diperoleh responden pada masing-masing dusun sebesar 17 orang pada dusun Ballaborong, 16 orang di dusun Karemanepasa, dan 9 orang pada dusun Karepattodo.

Tabel 1. Distribution of respondents

\begin{tabular}{clcc} 
No. & Dusun & Jumlah KK & Jumlah Responden \\
\hline 1. & Ballaborong & 167 & $(167 / 408) \times 41=17$ \\
\hline 2. & Karemanepasa & 152 & $(152 / 408) \times 41=16$ \\
\hline 3. & Karepatodo & 89 & $(89 / 408) \times 41=9$ \\
\hline & total & 408 & 42 \\
\hline
\end{tabular}

Pengumpulan data primer dilakukan dengan wawancara responden. Selain itu, wawancara juga dilakukan dengan Tokoh masyarakat dan pemerintah setempat seperti Sekretaris Desa dan para Kepala Dusun dari ke-tiga dusun sebagai informan kunci. Kuesioner dalam wawancara adalah kuesioner dengan 24 pertanyaan, 18 pertanyaan terbuka dan 6 pertanyaan tertutup. Pertanyaan terbuka digunakan untuk memberikan kesempatan kepada responden untuk mengeksplorasi pendapat mereka, sedangkan pertanyaan tertutup digunakan untuk mengukur tanggapan responden. Pada pertanyaan tertutup terdapat tiga pilihan jawaban, yaitu setuju, raguragu, dan tidak setuju. Kemudian jawaban responden tersebut dianalisis dengan metode kuantitatif menggunakan Skala Likert untuk mengukur tingkat persepsi masyarakat terhadap Suaka Margasatwa Ko'mara.

Persepsi adalah pandangan atau penilaian seseorang terhadap obyek tertentu yang dihasilkan oleh kemampuan mengorganisasi pengamatan dan selanjutnya ditentukan oleh faktor dalam diri individu dan faktor luar individu (Qomariah, 2009). Pada penelitian ini, faktor dalam diri individu yang diasumsikan berperan terhadap tingkat persepsi adalah umur, jumlah tanggungan, pendidikan, pekerjaan, lama tinggal, dan jarak dari kawasan. Faktor dari luar individu yang diasumsikan berperan terhadap tingkat persepsi adalah pelibatan masyarakat.

\subsection{Analisis Data}

Pengolahan data dari hasil wawancara pada kuesioner dilakukan kedalam bentuk tabulasi, kemudian dianalisis dengan tehnik skoring dan secara deskriptif. Tehnik skoring digunakan untuk mengukur tingkat persepsi masyarakat, analisis deskriptif digunakan untuk menggambarkan karakteristik responden dan faktor-faktor yang diasumsikan berpengaruh terhadap persepsi.

\section{HASIL DAN PEMBAHASAN}

\subsection{Deskripsi Lokasi Penelitian}

Menurut sejarahnya, masyarakat yang sekarang mendiami Dusun-Dusun disekitar kawasan Suaka Margasatwa Ko'mara merupakan masyarakat yang sebelumnya tinggal di atas gunung pada kawasan hutan yang sekarang adalah kawasan Suaka Margasatwa Ko'mara. Sekitar tahun 1960-an, beberapa orang tokoh masyarakat mulai turun dan membuat rumah didaerah yang sekarang disebut Dusun Balla'borong, Dusun Jambua (sekarang dimekarkan menjadi Dusun Karemanepasa dan Dusun Karepattoddo), dan Dusun Jenemaeja. Kemudian tokoh-tokoh masyarakat yang telah terlebih dahulu pindah, menghimbau agar masyarakat ikut pindah ke daerah yang didiami sekarang. Hal ini dikarenakan susahnya akses jalan menuju perkampungan yang terdahulu. Selanjutnya, secara bertahap masyarakat mulai berpindah dan membentuk perkampungan - perkampungan baru, hingga akhirnya perkampungan - perkampungan yang berada diatas gunung mulai ditinggalkan dan kosong hingga saat sekarang ini.

Masyarakat yang berdomisili di sekitar kawasan Suaka Margasatwa Ko'mara terdiri dari penduduk asli dan pendatang. Suku Makassar adalah penduduk asli yang mendominasi daerah 
tersebut. Penduduk pendatang antara lain terdiri dari suku Bugis, dan Jawa yang melakukan hubungan pernikahan dengan masyarakat setempat.

Barugaya yang merupakan Desa terdekat dengan kawasan, berpenduduk 3.138 jiwa dengan jumlah rumah tangga sebesar 859 Kepala Keluarga (KK). Penduduk Desa Barugaya yang berdomisili di sekitar kawasan Suaka Margasatwa Ko'mara tersebar di tiga dusun yakni Dusun Balla'borong dengan jumlah rumah tangga sebesar 167 KK, Dusun Karemanepasa dengan jumlah rumah tangga sebesar $152 \mathrm{KK}$, dan Dusun Karepattoddo dengan jumlah rumah tangga sebesar 89 KK (Kabupaten Takalar Dalam Angka, 2014).

\subsection{Karakteristik Responden}

Pada penelitian ini, secara keseluruhan jumlah responden adalah 42 orang yang merupakan penduduk asli pada tiga dusun yang berbatasan langsung dengan kawasan Suaka Margasatwa Ko'mara. Umur responden dibagi ke dalam empat kelompok, yaitu pada kelompok umur 30 - 39 tahun terdapat responden sebanyak 2 orang (4,76\%), 40 - 49 tahun sebanyak 17 orang $(40,48 \%), 50-59$ tahun sebanyak 17 orang $(40,48 \%)$, dan responden dengan umur lebih dari 60 tahun sebanyak 6 orang (14,29\%). Berdasarkan pendidikan dibagi empat kelompok, yaitu sebanyak 27 orang responden $(64,29 \%)$ tidak bersekolah atau pendidikan maksimal sekolah dasar, 10 orang $(23,81 \%)$ pada tingkat SMP, 4 orang $(9,52 \%)$ pada tingkat SMA, dan 1 orang responden berpendidikan sarjana.

Mayoritas mata pencaharian responden adalah petani atau sektor pertanian $(83,33 \%$,) dan sisanya adalah pegawai negeri, swasta, wirasawasta dan lain-lain. Berdasarkan jumlah tanggungan, sebanyak 33 orang responden $(78,57 \%)$ masuk dalam kategori keluarga kecil dengan jumlah tanggungan $1-4$ orang, 8 orang $(19,05 \%)$ dengan tanggungan $5-6$ orang dan, 1 orang $(2,38 \%)$ dengan tanggungan lebih dari 6 orang. Berdasarkan lama berdomisili, sebanyak 38 orang responden $(90,48 \%)$ telah menetap selama lebih dari 30 tahun, 3 orang $(7,14 \%)$ responden antara $10-30$ tahun dan, 1 orang responden $(2,38 \%)$ kurang dari 10 tahun.

\subsection{Tingkat Persepsi Masyarakat}

Tingkat persepsi seseorang atau sekelompok orang dapat berbeda-beda. Tingkat persepsi masyarakat terhadap Suaka Margasatwa Ko'mara didefinisikan berdasarkan Ngakan (2006), yaitu : 1) persepsi tinggi, apabila mereka memahami dengan baik bahwa dirinya bergantung hidup dari sumberdaya hayati hutan dan menginginkan agar sumberdaya tersebut dikelola secara lestari; 2) persepsi sedang, apabila mereka menyadari dirinya bergantung hidup dari sumberdaya hayati hutan tetapi tidak memahami kalau sumberdaya tersebut perlu dikelola secara lestari agar manfaatnya bisa diperoleh secara berkelanjutan; 3) persepsi rendah, apabila jawaban responden masuk dalam kategori tidak sadar kalau dirinya bergantung hidup dari sumberdaya hayati hutan, atau ada kepentingan lain yang membuat mereka cenderung beranggapan bahwa tidak perlu menjaga kelestarian sumberdaya hayati hutan.

Indikator yang digunakan untuk mengukur tingkat persepsi mayarakat adalah akumulasi dari jawaban responden pada kuesioner. Tingkat persepsi responden diidentifikasi menurut Setiawan (2013) dengan menganalisa pertanyaan tertutup pada kuesioner. Jawaban dinilai 3 jika " setuju" dan 1 jika "tidak setuju". Jawaban responden dijumlahkan kemudian dibagi kedalam 3 interval kelas yaitu tinggi, sedang, dan rendah. Untuk mengetahui interval kelas tingkat persepsi, maka nilai skor tertinggi dikurangi nilai skor terendah kemudian dibagi jumlah kelas interval. Dari hasil perhitungan dikategorikan dalam tiga kelas yaitu : Rendah (6 - 8), Sedang (9 - 11) dan Tinggi (12 - 15). 
Tabel 2. Category of community perception level

\begin{tabular}{ccc}
\hline Nomor & Kategori & Skor \\
\hline 1 & Tinggi & $12-15$ \\
\hline 2 & Sedang & $9-11$ \\
\hline 3 & Rendah & $6-8$ \\
\hline
\end{tabular}

Responden dengan tingkat persepsi tinggi berarti memiliki pengetahuan tentang Suaka Margasatwa. Indikator pengetahuan responden tersebut dalam kuesioner adalah pernah mendengar dan tahu istilah Suaka Margasatwa, mengetahui kapan kawasan tersebut diukur dan dipatok, kondisi hutan terkini, adanya pelibatan masyarakat dalam pengelolaan, dan setujukah penunjukan kawasan. Tingkat persepsi masyarakat terhadap Suaka Margasatwa Ko'mara dapat dilihat pada Tabel 3 berikut.

Tabel 3. Community perceptions of Ko'mara Wildlife Reserve

\begin{tabular}{lrrrrrrrr}
\hline & \multicolumn{2}{c}{ Ballaborong } & \multicolumn{2}{c}{ Karemanepasa } & \multicolumn{2}{c}{ Karepatodo } & \multicolumn{2}{c}{ Total } \\
\cline { 2 - 10 } & \multicolumn{1}{c}{ n } & \multicolumn{1}{c}{ \% } & \multicolumn{1}{c}{$\%$} & \multicolumn{1}{c}{ n } & \multicolumn{1}{c}{$\%$} & $\mathrm{n}$ & \multicolumn{1}{c}{$\%$} \\
\hline Tinggi & 3 & 17,65 & 1 & 6,25 & 1 & 11,11 & 5 & 11,67 \\
\hline Sedang & 3 & 17,65 & 14 & 87,50 & 8 & 88,89 & 25 & 64,68 \\
\hline Rendah & 11 & 64,71 & 1 & 6,25 & 0 & 0,00 & 12 & 23,65 \\
\hline & \multicolumn{3}{c}{ Jumlah } & & & & 42 & 100,00 \\
\hline
\end{tabular}

Tabel 3 menunjukkan bahwa, masyarakat yang tinggal di Dusun Karemanepasa dan Dusun Karepatodo memiliki tingkat persepsi "sedang" terhadap Suaka Margasatwa Ko'mara. Sedangkan masyarakat yang tinggal di Dusun Ballaborong memiliki tingkat persepsi yang "rendah" terhadap Suaka Margasatwa Ko'mara. Tingkat persepsi masyarakat secara keseluruhan pada tiga Dusun tersebut jika dirata-ratakan termasuk dalam tingkat persepsi "sedang". Sebanyak 23,65\% responden memiliki tingkat persepsi rendah, $64,68 \%$ memiliki tingkat persepsi sedang dan hanya $11,67 \%$ responden yang memiliki tingkat persepsi tinggi.

\subsection{Analisis Faktor-faktor yang berperan terhadap persepsi}

Faktor-faktor yang berperan terhadap persepsi masyarakat dalam penelitian ini adalah 1) umur, 2) jumlah tanggungan, 3) pendidikan, 4) pekerjaan, 5) lama tinggal, 6) jarak dari kawasan, 7) pelibatan masyarakat. Peneliti menganalisis dan memaparkan secara deskriptif pengaruh faktorfaktor tersebut.

1. Umur

Yuwono (2006) menyatakan bahwa umur adalah penggambaran karakteristik individu berdasarkan dari pengalamannya, bahwa semakin tua seseorang makin sulit menerima suatu perubahan atau dengan kata lain sudah puas dengan kondisi yang dicapai. Dengan bertambahnya umur maka kepedulian dan penerimaan akan hal-hal yang baru semakin berkurang. Masyarakat yang sebagian besar telah berdomisili pada daerah tersebut selama lebih dari 30 tahun tentunya tidak akan dengan mudah menerima istilah kawasan konservasi, ditambah lagi dengan aturan-aturan baru dari kawasan suaka margasatwa.

Pada umumnya semakin tua umur seorang petani maka persepsi terhadap hutan semakin buruk dan semakin muda umur petani maka persepsi terhadap hutan semakin baik (Ramdhani, 2011). Malihat bahwa sebagian besar responden $(85,71 \%)$ menurut analisis demografi berada pada rentang usia produktif. Kondisi ini harus dimanfaatkan karena pada kelompok usia ini masih terdapat peluang dan potensi perubahan persepsi kearah yang lebih baik. Pendekatan kepada masyarakat melalui sosialisasi dan penyuluhan sangatlah penting, 
langkah tersebut dilakukan secara berkelanjutan pada kondisi usia masyarakat yang dominasi oleh kelompok produktif tersebut.

\section{Pendidikan}

Tingkat pendidikan adalah faktor yang mempengaruhi persepsi masyarakat terhadap SM. Ko'mara. Pendidikan yang tinggi dianggap memiliki lebih banyak pengetahuan yang dapat mempengaruhi persepsi atau semakin tinggi tingkat pendidikan, diasumsikan semakin tinggi tingkat persepsi (Setiawan, 2013).

Hasil wawancara dengan responden menunjukkan bahwa sebagian besar responden $(64,29 \%)$ hanya memiliki jenjang pendidikan maksimal Sekolah Dasar. Pendidikan masyarakat yang relatif rendah yaitu sebagian besar hanya mengenyam Sekolah Dasar, dapat mempengaruhi proses penerimaan masyarakat terhadap informasi mengenai kawasan Suaka Margasatwa. Menurut Wahyuni (2012), perbedaan tingkat pendidikan dan kurangnya sosialisasi tentang manfaat kawasan konservasi dapat menyebabkan perbedaan persepsi. Dari hasil wawancara dengan responden dapat juga diketahui bahwa selama ini pengelola tidak pernah melakukan penyuluhan kepada masyarakat (wawancara pribadi, 2 Mei 2016). Tinggi rendahnya tingkat pendidikan responden dan tidak adanya penyuluhan tentang kawasan akan berpengaruh terhadap wawasan dan pola pikir masyarakat dalam mempersepsikan SM. Ko'mara.

\section{Pekerjaan}

83\% masyarakat yang menjadi responden bekerja sebagai petani dan sisanya masih berhubungan dengan sektor pertanian. Lahan pertanian masyarakat disekitar kawasan hutan, mendapatkan pengairan dari dam pengendali yang sumber airnya berasal dari sungai-sungai di dalam hutan. Data pokok Desa dan Kelurahan tahun 2015 menyebutkan bahwa 78 persen atau $5.603 \mathrm{Ha}$ dari luas Desa Barugaya adalah lahan pertanian, terdiri atas persawahan, tanah kering, dan kebun. Produksi padi Desa Barugaya tahun 2015 sebesar 14.000 ton dan dari perkebunan Tebu sebesar 312.500 ton. Luasnya lahan pertanian di Desa Barugaya dan masih produktif, menjadikan sebagian besar masyarakat bekerja dibidang pertanian.

Hasil wawancara menunjukkan bahwa $83 \%$ responden memberikan jawaban manfaat hutan adalah sebagai sumber air, hal ini menunjukkan adanya ketergantungan masyarakat dengan kawasan hutan. Kesadaran masyarakat akan pentingnya hutan dengan keberlangsungan pekerjaan mereka akan menumbuhkan persepsi positif terhadap hutan. Sesuai dengan pernyataan Umar (2009), bahwa aktivitas responden yang berhubungan dengan hutan menyadari bahwa aktivitas mereka tergantung dari keberadaan hutan. Dengan kata lain, jika tidak ada hutan kemungkinan mereka tidak dapat melakukan aktivitas.

\section{Jarak dari kawasan}

Persepsi positif maupun negatif masyarakat terbentuk dari ketergantungannya terhadap hutan. Ketergantungan masyarakat akan sumberdaya dalam hutan dapat dipengaruhi oleh jarak terhadap kawasan hutan. Menurut Nugroho (2008), terdapat hubungan antara jarak dengan pengambilan sumberdaya hutan, jika jarak rumah ke hutan semakin jauh, maka pengambilan sumberdaya hutan akan berkurang. Semakin jauh dengan kawasan hutan maka ketergantungan masyarakat akan sumberdaya hutan semakin berkurang dan akan membentuk persepsi positif atau baik.

Hal berbeda ditemui pada lokasi penelitian, dari hasil wawancara dengan responden diketahui bahwa Dusun Ballaborong yang berada pada radius 2-3 Km dari kawasan, interaksi masyarakat dengan kawasan terbilang tinggi. Berbanding dengan dua Dusun lain yaitu Karemanepasa dan Karepatodo yang berada pada radius 1-2 Km dari kawasan, responden yang diwawancarai pada kedua Dusun tersebut mengaku bahwa mereka sudah tidak lagi masuk kawasan mengambil hasil hutan. 
Tingginya interaksi masyarakat sekitar kawasan pada Dusun Ballaborong dikarenakan sebagian besar lahan pertanian hanya dapat diolah sekali dalam setahun yaitu berupa lahan pertanian tadah hujan. Tidak adanya aktifitas dari bidang pertanian maka untuk menambah penghasilan masyarakat salah satunya adalah memungut sumber daya dari dalam hutan. Pengelola kawasan diharapkan bisa mengadakan kegiatan-kegiatan pemberdayaan masyarakat yang bernilai ekonomi sehingga dapat meminimalkan ketergantungan masyarakat terhadap kawasan hutan.

Pada Dusun Karemanepasa dan Karepatodo, masih adanya tokoh masyarakat yang sangat berpengaruh dan peduli terhadap kawasan hutan disekitarnya. Tokoh masyarakat yang juga merupakan tokoh adat melarang masyarakat sekitar mengambil sumberdaya dari dalam hutan. Tokoh formal maupun informal tersebut punya potensi dalam mempengaruhi persepsi masyarakat. Pendekatan pihak pengelola kepada tokoh-tokoh tersebut, merupakan langkah awal yang sangat penting dalam pengelolaan kawasan konservasi yang berbatasan dengan pemukiman masyarakat. Sejalan dengan Wibowo (2006) yang menyatakan bahwa tokoh masyarakat, terutama masyarakat adat, memegang tampuk kepemimpinan tertinggi dalam organisasi sosial masyarakat Desa hutan yang memiliki otoritas penuh terhadap warga Desa hutan.

\section{Lama tinggal}

Masyarakat sudah bermukim di sekitar kawasan hutan secara turun temurun sebelum adanya penunjukkan hutan menjadi kawasan Suaka Margasatwa, masyarakat yang mendiami DusunDusun di sekitar kawasan SM. Ko'mara pada awalnya berasal dari dalam kawasan tersebut. Hamid et al (2011) menyatakan bahwa penduduk asli yang sudah lama tinggal dan menetap akan memunculkan keterikatan akan daerah yang dihuninya dan terhadap pemanfaatan sumber daya di sekitarnya. Semakin lama seseorang tinggal dan menetap di suatu daerah pada umunya akan memberikan pengaruh positif sehingga dapat merangsang rasa memiliki yang mendalam yang pada akhirnya tumbuh kesadaran untuk memelihara dan mengelola (Wijaksono, 2013).

Hasil wawancara menunjukkan bahwa sebagian besar responden $(90,48 \%)$ telah menetap lebih dari 30 tahun. Sejarah kawasan hutan sangat erat hubungannya dengan masyarakat sekitar. Lama bermukimnya seseorang di suatu tempat akan membuat orang tersebut mempunyai keterikatan dengan tempat tersebut karena adanya kenangan-kenangan masa lalu tentang sejarah hidupnya ditempat tersebut (Himbawan, 2010). Adanya keterkaitan sejarah dan manfaat langsung dari kawasan hutan berupa pengairan terhadap sawah masyarakat, dapat membentuk persepsi yang positif terhadap hutan disekitarnya

\section{Pelibatan masyarakat}

Menurut Benu (2007), Pentingnya peran serta masyarakat tersebut didasarkan kepada 1) masyarakat berhak mengetahui tentang setiap rencana pembangunan yang secara potensial mempengaruhi kehidupan mereka, 2) masyarakat adalah "local expert" tentang lingkungan di sekitarnya, sehingga layak didengar pendapat dan gagasannya agar kegiatan bisa berjalan, 3) keberlanjutan dari proyek, program, dan kebijakan akan terjamin jika masyarakat diikutsertakan. Pelibatan masyarakat sekitar SM. Ko'mara adalah sebagai pendamping dalam beberapa kegiatan Balai, seperti inventarisasi satwa, penangkaran satwa, pariwisata dan patroli pengamanan. Selain itu beberapa orang diikutkan dalam pelatihan kader konservasi. Pelibatan masyarakat pada pengelolaan SM Ko'mara pada dasarnya bernilai positif, masyarakat mendapatkan beberapa insentif dari pengelola kawasan. Insentif tersebut salah satunya adalah transfer pengetahuan kehutanan. Atas arahan dari pengelola kawasan, beberapa petani pada Dusun Ballaborong memanfaatkan lahan pekarangan mereka sebagai persemaian sederhana. Bibit-bibit yang mereka semaikan akan ditanam pada kebun-kebun mereka. Meskipun hasil yang nantinya diperoleh tidak secepat tanaman pertanian akan tetapi 
tanaman kehutanan tersebut dapat menjadi tabungan bagi para petani. Sehingga mereka tidak perlu lagi bergantung pada sumber daya hutan seperti kayu. Selain itu, dapat pula dijual untuk menambah penghasilan petani dan pada akhirnya akan mengurangi ketergantungan meraka pada kawasan hutan. sedangkan intensif yang berupa nominal uang, sampai saat ini belum ada standar besaran jumlahnya.

Pelatihan-pelatihan terhadap masyarakat sekitar hutan dapat juga menjadi strategi pelibatan dari pengelola. Pelatihan-pelatihan dapat dibungkus dengan penyuluhan yang dapat menambah dan mengubah pola pikir masyarakat sekitar kawasan. Penyuluhan Kehutanan dengan masyarakat sebagai kelompok sasaran akan menjadi tulang punggung dan ujung tombak keberhasilan kegiatan pembangunan kehutanan (Mahbub, 2017).

\section{KESIMPULAN DAN SARAN}

\subsection{Kesimpulan}

Berdasarkan hasil kajian dan pengamatan di lapangan, sebagaimana diuraikan sebelumnya, maka penelitian Persepsi Masyarakat Terhadap Status Kawasan Suaka Margasatwa Ko'mara Kabupaten Takalar dapat disimpulkan bahwa tingkat persepsi masyarakat yang menjadi responden di setiap dusun berbeda-beda. Masyarakat yang tinggal di Dusun Karemanepasa dan Karepatodo memiliki tingkat persepsi "sedang". Sedangkan pada Dusun Ballaborong memiliki tingkat persepsi "rendah".

Umur responden yang berada pada rentang usia produktif harus dimanfaatkan karena pada kelompok usia ini masih terdapat peluang dan potensi perubahan persepsi kearah yang lebih baik. Rendahnya tingkat pendidikan responden akan berpengaruh terhadap wawasan dan pola pikir masyarakat dalam mempersepsikan kawasan Suaka Margasatwa Ko'mara. Pekerjaan responden sebagai petani yang sangat tergantung kepada hutan sebagai penyedia air bagi lahan pertanian mereka dapat membentuk persepsi positif terhadap kawasan. Pelibatan masyarakat pada pengelolaan Suaka Margasatwa Ko'mara pada dasarnya juga bernilai positif karena masyarakat karena dapat menjadi sarana penyuluhan mengenai kawasan konservasi oleh pengelola kawasan.

\subsection{Saran}

Pengelola kawasan perlu meningkatkan kegiatan yang melibatkan masyarakat atau mengadakan penyuluhan terhadap masyarakat, hal tersebut dapat menambah pengetahuan masyarakat mengenai pentingnya keberadaan kawasan hutan disekitar mereka. Perlu adanya pendekatan kepada tokoh masyarakat yang dapat menjadi figur dalam menumbuhkan kesadaran dan perlindungan hutan oleh masyarakat.

\section{DAFTAR PUSTAKA}

Arikunto, Suharsimi. (1998). Prosedur penelitian, suatu pendekatan praktek. Penerbit Rineka Cipta, Edisi revisi IV, April 1998.

Benu, Junianto. 2007. Persepsi, Sikap, Dan Perilaku Masyarakat Sekitar Hutan Terhadap Keberadaan Hutan Penelitian Haurbentes. Skripsi. Departemen Manajemen Hutan. Fakultas Kehutanan. Institut Pertanian Bogor. 2007.

Hamid, R., Zulkarnaini, Saam, Z., 2011. Analisis Sosial Ekonomi Masyarakat Desa Hutan Pasca Kegiatan HPH PT. Siak Raya Timber Di Kabupaten Pelalawan, Provinsi Riau. Jurnal IImu Lingkungan. Program Studi llmu Lingkungan PPs Universitas Riau (5) 2. 2011. 
Himbawan, G., 2010. Penyebab Tetap Bermukimnya Masyarakat Di Kawasan Rawan Banjir Kelurahan Tanjung Agung Kota Bengkulu. Tesis Program Pascasarjana Magister Teknik Pembangunan Wilayah Dan Kota Universitas Diponegoro Semarang. 2010.

Mahbub, 2007. Penyuluhan Kehutanan Partisipatif. Jurnal Hutan Dan Masyarakat,2(3): 313-318. Makassar 2007.

Muntu, WD, 2012. Penguasaan Tanah di dalam Kawasan Cagar Alam Gunung Dua sudara Di Kota Bitung. Skripsi. Fakultas Hukum Universitas Hasanuddin. 2012.

Nugroho, B.T.A., Undaharta, N.K.E., Siregar, M., 2008. Interaksi Masyarakat Sekitar Hutan Terhadap Pemanfaatan Keanekaragaman Hayati Di Kawasan Ekosistem Hutan Alami Bedugul-Pancasari, Bali. Biodiversitas Vol. 9 No. 3 Hal : 227-231 Juli 2008, Tabanan 2008.

Ngakan, P.O., Komarudin, H., Achmad, A., Wahyudi, Tako, A., 2006. Ketergantungan, Persepsi dan Partisipasi Masyarakat terhadap Sumberdaya Hayati Hutan. Studi Kasus di Dusun Pampli Kabupaten Luwu Utara, Sulawesi Selatan. Center for International Forestry Research. Intiprima Karya, Jakarta 2012.

Qomariah, Lailatul. 2009. Pengembangan Ekowisata Berbasis Masyarakat Di Taman Nasional Meru Betiri ( Studi Kasus Blok Rajegwesi Sptn I Sarongan ). Program Studi Konservasi Sumberdaya Hutan. Departemen Konservasi Sumberdaya Hutan Dan Ekowisata Fakultas Kehutanan. Institut Pertanian Bogor. 2009.

Ramdhani, H.S, 2011. Studi Sosial Ekonomi Dan Persepsi Masyarakat Terhadap Corporate Social Responsibility (CSR) Perusahaan Hutan Tanaman Industri PT. Nityasa Idola di Kalimantan Barat. Departemen Manajemen Hutan Fakultas Kehutanan Institut Pertanian Bogor. 2011.

Sawitri, 2013. Persepsi Masyarakat Terhadap Restorasi Zona Rehabilitasi Di Taman Nasional Gunung Gede Pangrango. Indonesian Forest Rehabilitation Journal vol. 1 no. 1, september 2013: 92.

Sugiyono, 2012. Statistik untuk Penelitian. Cetakan ke-20. Maret 2012.

Setiawan, 2013. Analysis Community's Coping Strategies And Local Risk Governance Framework In Relation To Landslide: A Case of Tawangmangu Sub-District, Karanganyar Regency, Indonesia. Tesis. Gadjah Mada University - Faculty Of Geo-Information And Earth Observation University Of Twente. 2013.

Umar, 2009. Persepsi Dan Perilaku Masyarakat Dalam Pelestarian Fungsi Hutan Sebagai Daerah Resapan Air (Studi Kasus Hutan Penggaron Kabupaten Semarang). Tesis Program studi IImu Lingkungan. Universitas Diponegoro. 2009.

Wahyuni, N.I., Mamonto, R., 2012. Persepsi Masyarakat Terhadap Taman Nasional Dan Sumberdaya Hutan: Studi Kasus Blok Aketawaje, Taman Nasional Aketajawe Lolobata. Info BPK Manado Volume 2 No 1, Juni 2012.

Wijaksono, S., 2013. Pengaruh Lama Tinggal Terhadap Tingkat Partisipasi Masyarakat Dalam Pengelolaan Lingkungan Permukiman. Jurnal ComTech Vol.4 No. 1 Juni 2013: 24-32.

Yuwono, 2006. Persepsi Dan Partisipasi Masyarakat Terhadap Pembangunan Hutan Rakyat Pola Kemitraan Di Kabupaten Musi Rawas Propinsi Sumatera Selatan. Tesis Program Studi Pengelolaan Sumberdaya Alam Dan Lingkungan. Sekolah Pascasarjana Institut Pertanian Bogor. Bogor 2006. 